mechanism may be relevant to AIDS because HTLV-III isolates have shown a range of genomic variability, especially in the envelope region ${ }^{22}$, and a relatedness of HTLV-III to visna virus was demonstrated recently ${ }^{23}$. It will be necessary to obtain serial isolates and serum samples from individuals throughout the course of the disease to determine whether HTLV-III neutralizing antibodies exert selective pressure on viral mutants.

The presence of HTLV-III neutralizing antibodies in sera of individuals exposed to HTLV-III demonstrates an immunological response during the course of disease development which may be used therapeutically. Furthermore, it gives hope that appropriate vaccine approaches may be effective in preventing viral infection. Further studies will determine whether virus neutralizing antibodies in the sera of patients have prognostic value or will be indicative of appropriate treatment regimes.

We thank Dr M. V. O'Shaughnessy for helpful discussion, Dr R. E. Tarone for statistical analysis and Ms Anna Mazzuca for assistance in preparing the manuscript.

Received 28 January; accepted 21 May 198.

1. Popovic, M., Sarngadharan, M. G., Read, E. \& Gallo, R. C. Science 224, 497-500 (1984), 2. Gallo, R. C. et al Science 224, 500-502 (1984).

3. Sarngadharan, M. G., Popovic, M., Bruch, L., Schupbach, J. \& Gallo, R. C. Science 224 506-508 (1985).

4. Safai, B. et al. Lancet 1, 1438-1440 (1984).

5. Goedert, J. J. et al. Lancet ii, 711-716 (1984).

6. Tsoukas, C. et al. New Engl. J. Med. 311, 1514-1515 (1984)

7. Goedert, J. J. et al. Blood 65, 492-495 (1985).

8. Gazzolo, L., Gessain, A., Robin, Y., Robert-Guroff, M. \& de-The, G. New Engl. J. Med. $311,1252-1253$ (1984).

9. Redfield, R. R. et al. J. Am. med. Ass. 253, 1571-1573 (1985)

10. Harris, C. A. et al. (in preparation).

11. Clumeck, N. et al. New Engl. J. Med. 310, 492-497 (1984)

12. Saxinger, W. C. et al. Science 227, 1036-1039 (1985).

13. Clumeck, N. et al (in preparation).

14. Gazzolo, L. et al. Int. J. Cancer (in the press).

15. Clapham, P. Nagy, K. \& Weiss, R. A Proc natn. Acad Sci. U.S. A. 81, 2886-2889 (1984)

16. Weiss, R A et al Nature 316, 69-72 (1985)

17. McDougal, J S et al J immun Meth 76, 171-183 (1985)

18. Veronese di Marzo, F. et al. Proc. natn. Acad. Sci. U.S.A. (in the press)

19. Steeves, R. A., Strand, M. \& August, I. T. J. Virol 14, 187-189 (1974)

20. Ihle, J. N. \& Lazar, B. J. Virol 21, 974-980 (1977).

21. Narayan, O., Clements, J. E., Griffin, D. E. \& Wolinsky, J. S. Infect. Immun. 32, 1045-1050 (1981).

22. Shaw G. M et al Science 226, 1165-1171 (1984).

23. Gonda, M. A. et al. Science 227, 173-177 (1985).

24. Robert-Guroft, M. Ruscetti, F. W. Posner, L. E. Poiesz, B. J. \& Gallo, R. C. J. exp. Med. 154, 1957-1964 (1981).

\section{An anti-idiotype vaccine against experimental schistosomiasis}

\author{
J. M. Grzych, M. Capron, P. H. Lambert*, \\ C. Dissous, S. Torres \& A. Capron
}

Centre d'Immunologie et de Biologie Parasitaire, Unité Mixte INSERM U 167-CNRS 624, Institut Pasteur, BP 245,

59019 Lille Cedex, France

* Centre OMS de Recherche et de Formation en Immunologie,

Département de Pathologie CMV, 1211 Genève 4, Switzerland

Schistosomiasis is a parasitic infection of man which is widespread in tropical countries, and which so far has resisted attempts at control. We have been approaching the problem from an immunological angle. We have previously reported ${ }^{1}$ the production of a rat monoclonal IgG2a antibody against Schistosoma mansoni which exhibits marked cytoxicity for schistosomula in the presence of eosinophils and a high degree of protection by passive transfer in naive rats. This antibody, IPLSm1, was shown to bind specifically to a schistosomulum membrane target antigen defined as a glycoprotein of relative molecular mass $38,000(38 \mathrm{~K})^{2}$, which is strongly immunogenic in schistosome infection of various animal species including $\operatorname{man}^{3}$. Although theoretically the $38 \mathrm{~K}$ protein represents an excellent candidate for a potential vaccine against schistosomiasis, the glycanic nature of the epitope recognized by
IPLSm1 limits its production by DNA recombinant technology. It was, moreover, shown that, together with protective antibodies, the 38K molecule was able to induce the production of blocking IgG2c antibodies that inhibit the functional properties of IPLSm1 both in vitro and in vivo ${ }^{4}$. Therefore, following Jerne's network theory ${ }^{5}$, we considered an alternative approach, the possibility of immunization using anti-idiotype antibodies. In the present study, rat monoclonal anti-idiotype antibodies were produced against IPLSm1 $\left(\mathbf{A B}_{1}\right)$. Anti-idiotype antibodies $\left(\mathbf{A B}_{2}\right)$ were selected by their capacity to inhibit the binding of radioiodinated $\mathbf{A B}_{1}$ to its $38 K$ target antigen. Sera from naive LOU rats immunized with a purified $\mathrm{AB}_{2}$ preparation contained specific anti-schistosome antibodies $\left(\mathrm{AB}_{3}\right)$ which bound to $38 \mathrm{~K} . \mathrm{AB}_{3}$ antibodies were strongly cytotoxic for schistosomula in the presence of rat eosinophils and conferred highly significant protection by passive transfer. Most importantly, rats immunized with $\mathbf{A B}_{2}$ demonstrated marked protection $(50-80 \%)$ to a challenge infection.

Monoclonal antibodies to IPLSm1 were obtained in a homologous hybridization system. Male LOU rats were injected subcutaneously with $1 \mathrm{mg}$ of purified IPLSm 1 plus $1 \mathrm{mg}$ of glutaraldehyde-aggregated human IgG in the presence of complete Freund's adjuvant. Two weeks later, the rats received a second injection of the same preparation. The immunization was completed by two subcutaneous injections of $1 \mathrm{mg}$ of

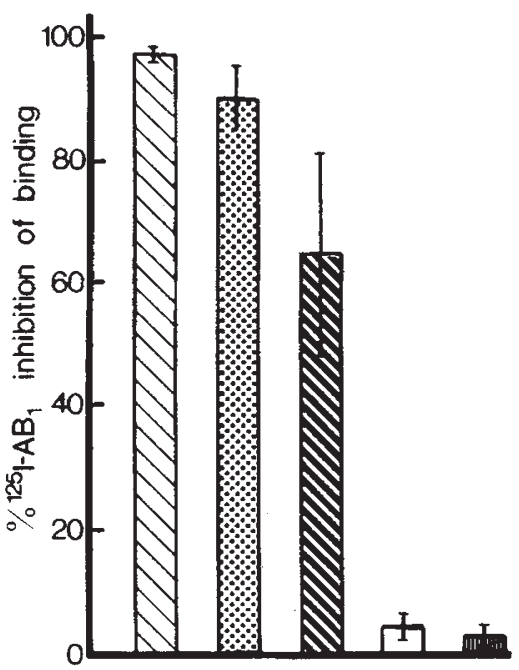

Fig. 1 Inhibition of radiolabelled $\mathrm{AB}_{1}$ antibody (IPLSm1 IgG2a antibody) to the $38 \mathrm{~K}$ antigen. Experiments were performed on PVC microtitre plates precoated with $\mathrm{C}_{3}-109 \mathrm{IgM}$ antibody (an $S$. mansoni rat monoclonal antibody which recognizes the $38 \mathrm{~K}$ molecule but does not interfere with IPLSm1 binding). Each well of the PVC plates was coated with $100 \mu \mathrm{l}$ of a $10 \mu \mathrm{g} \mathrm{ml}^{-1}$ solution of $\mathrm{C}_{3}-109$ IgM diluted with $10 \mathrm{mM}$ phosphate-buffered saline (PBS), a procedure which gives better fixation of the $38 \mathrm{~K}$ antigen. After $2 \mathrm{~h}$, the plates were washed twice in PBS buffer and saturated for $30 \mathrm{~min}$ with $200 \mu \mathrm{l}$ of a $2 \%$ bovine serum albumin (BSA) solution in PBS. The plates were then washed twice in PBS- $0.1 \%$ BSA. A Nonidet P-40 extract of schistosomula was added $(100 \mu 1$ antigen solution containing $100 \mu \mathrm{g}$ of protein). After $2 \mathrm{~h}$ exposure at $37^{\circ} \mathrm{C}$, plates were washed twice in PBS- $0.1 \%$ BSA buffer. For the test, $50 \mu \mathrm{l}$ of ${ }^{125}$ I-labelled IPLSm1 IgG2a was incubated with $50 \mu \mathrm{l}$ of sera at a dilution of $1 / 25$ in PBS- $0.1 \%$ BSA buffer for $1 \mathrm{~h}$ at $37^{\circ} \mathrm{C}$ and for $16 \mathrm{~h}$ at $4{ }^{\circ} \mathrm{C}$ and the plates were then washed three times in PBS- $0.1 \%$ BSA buffer. The wells were counted in a $\gamma$-counter. The percentage of IPLSm 1 inhibition binding was calculated using the following formula: $a-b / a \times 100=\%$ of inhibition, where $a=$ c.p.m. obtained when ${ }^{125} \mathrm{I}-\mathrm{AB}_{1}$ was incubated with $50 \mu$ of PBS- $0.1 \%$ BSA buffer, and $b$, c.p.m. obtained when ${ }^{125} I-A_{1}$ was incubated with $50 \mu \mathrm{l}$ serum from a rat bearing a subcutaneous IPLSm1 hybridoma (\$), $50 \mu$ l serum from a rat immunized with

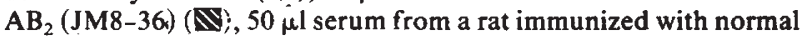
$\operatorname{IgM}(\square), 50 \mu \mathrm{l}$ serum from a 4-week-infected rat (圈) or $50 \mu \mathrm{l}$ of normal rat serum $(\mathbb{W})$ (mean of five duplicate experiments \pm s.d.). 


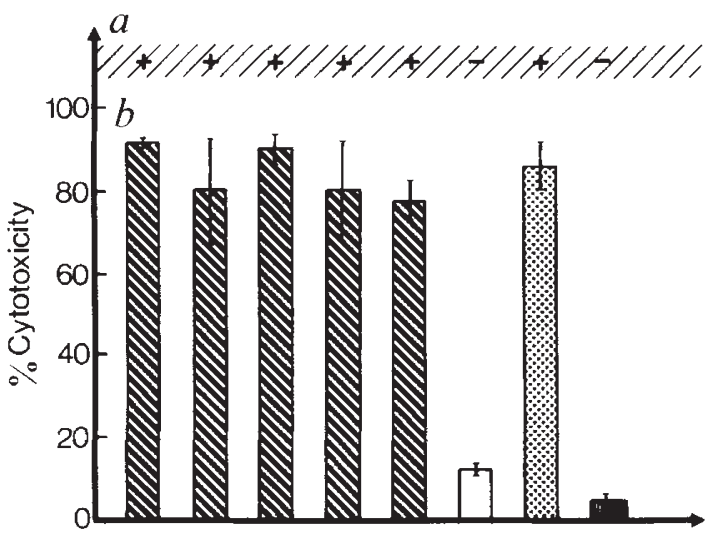

Fig. 2 Humoral response to $\mathrm{AB}_{2}$ immunization. $a$, Immunofluorescence tests; $b$, eosinophil-dependent cytotoxicity. Indirect immunofluorescence tests were performed ${ }^{1}$ on deep-frozen sections of schistosomula $(8 \mu \mathrm{m}) . S$. mansoni schistosomula were prepared by penetration of cercariae through abdominal mouse skin. Sera (tested at a dilution of $1 / 20$ in $10 \mathrm{mM}$ PBS) were collected from LOU/M rats immunized by JM8-36 $\left(\mathrm{AB}_{2}\right)$ antibody $(\mathrm{N})$ purified from ascitic fiuid as described previously ${ }^{15}$. A 1-mg aliquot of the purified preparation in physiological saline was injected subcutaneously at 2 -week intervals. Control sera were obtained from rats injected in the same conditions with the IgM fraction of normal rat serum $(\square)$. Eosinophil-dependent cytotoxicity was measured after $48 \mathrm{~h}$ contact of skin schistosomula, preincubated overnight with the sera at a final dilution of $1 / 16$, with a rat eosinophil-rich population (40-60\% eosinophils). The percentage cytotoxicity was compared at equivalent dilutions with control sera, normal rat serum (鮞) or serum from rats infected for 4 weeks with $S$. mansoni (䎌). All results correspond to a mean of two duplicate experiments \pm s.d.

IPLSm 1 and $1 \mathrm{mg}$ of aggregated human IgG in incomplete Freund's adjuvant at 2 -week intervals. The Ouchterlony test was used to select rats showing the highest responses and spleen cells from these animals were fused with cells from the IR983F rat myeloma cell line ${ }^{6}$ as described previously ${ }^{1}$. The hydrid cell supernatants were screened for their ability to inhibit the binding of ${ }^{125}$ I-labelled IPLSm1 to the $38 \mathrm{~K}$ target antigen coated on a polyvinyl chloride (PVC) plate. From 200 hybrid cell supernatants obtained from two successive cell fusion experiments, we selected 29 supernatants inducing significant levels of inhibition $(>70 \%)$.

Analysis of the immunological components of these hybrid cell supernatants by the Ouchterlony test revealed that in most cases $(23 / 29)$ they contained antibodies of the IgM class. The inhibitory activity of hybrid cell supernatants on IPLSm1 binding to $38 \mathrm{~K}$ strongly suggested that the antibodies produced were able to fix to an epitope of IPLSm1 which was close to or part of its antigen-combining site, indicating that $\mathrm{AB}_{2}$ were paratopeinduced antibodies bearing an internal image of the original epitope.

We next investigated the potential use of such antibodies to induce active immunization in naive LOU rats. Two questions in particular were studied: Is it possible to use $\mathrm{AB}_{2}$ antibodies to induce the production of $\mathrm{AB}_{3}$ antibodies which will reproduce the effector mechanism described previously in vitro both in experimental schistosomiasis ${ }^{7}$ and with $\mathrm{AB}_{1}$ antibody, involving eosinophil-mediated cytotoxicity ${ }^{1}$ ? Does this immunization lead to a significant protection of naive rats against a challenge infection?

To answer the first question, we followed the kinetics of the antibody response in naive LOU rats immunized with $\mathrm{AB}_{2}$ antibodies. Successive injections of purified IgM anti-idiotype antibody (JM8-36) for 4 weeks elicited anti-schistosome antibodies $\left(\mathrm{AB}_{3}\right)$ which were detected by indirect immunofluorescence on cryopreserved $S$. mansoni schistosomulum sections. In all cases, the fluorescence reaction was observed at the surface

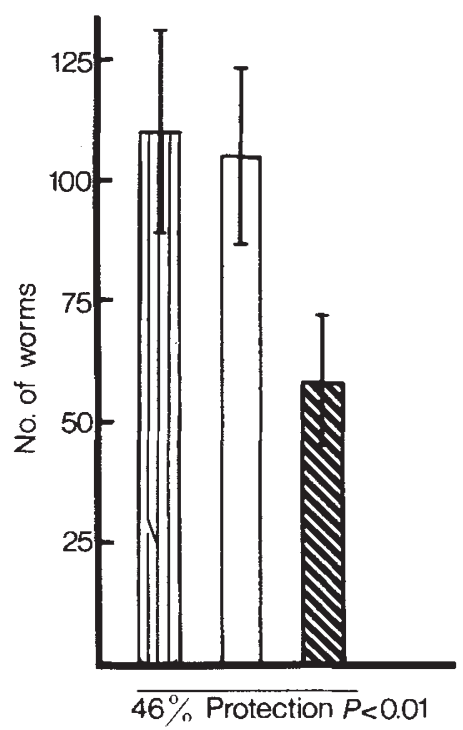

Fig. 3 Passive transfer of $\mathrm{AB}_{3}$ antibodies. Serum ( $1 \mathrm{ml}$ ) collected from JM8-36 immunized rats $(\mathbb{N})$ or from rats immunized with normal IgM ( $\square$ ) was injected intravenously into LOU rats infected $4 \mathrm{~h}$ previously with $800 \mathrm{~S}$. mansoni cercariae. Parasitic burdens were evaluated 3 weeks later by liver perfusion ${ }^{16}$. The number of worms obtained from these groups was compared with the parasite burden of rats injected with $1 \mathrm{ml}$ of physiological saline (iil). Percentage protection was calculated by the formula $(a-b) / a \times$ 100 , where $a=$ the number of worms recovered from the salineinjected control group and $b=$ the number of worms recovered from rat injected with $1 \mathrm{ml}$ of $\mathrm{AB}_{3}$ serum.

level. These observations, suggesting a close correlation between the structure of the anti-idiotype antibody and an epitope present on the surface of $S$. mansoni schistosomula, were confirmed by competition of $A_{1}$ by $A B_{3}$ on radiolabelled membrane preparations of schistosomula. AB3 preparations strongly inhibited the binding of $\mathrm{AB}_{1}$ to the $38 \mathrm{~K}$ molecule, indicating a close specificity for the same epitope (Fig. 1).

We explored the biological activity of these $\mathrm{AB}_{3}$ antibodies induced by anti-idiotype immunization by determining their possible participation in eosinophil-dependent cytotoxicity reactions against $S$. mansoni schistosomula. A significant level of cytotoxicity (70-90\%) was observed, close to that mediated by a 4 -week $S$. mansoni-infected rat serum (Fig. 2) or by the $\mathrm{AB}_{1}$ monoclonal antibody itself ${ }^{1}$.

The relevance of these in vitro findings was fully supported by the demonstration that passive transfer of $\mathrm{AB}_{3}$ antibodies to naive rats resulted in a significant protection of these animals to a challenge infection by $S$. mansoni cercariae (Fig. 3 ).

Finally, we studied the direct protective effect of an antiidiotype immunization. In two series of experiments involving 30 naive LOU rats, immunization with $\mathrm{AB}_{2}$ resulted in $50-76 \%$ protection to a challenge infection (Fig. 4).

The work presented here clearly demonstrates that immunization with an anti-idiotype monoclonal antibody can reproduce several parameters of the acquired immunity observed in experimental rat schistosomiasis. First, immunization with $\mathrm{AB}_{2}$ resulted in the production of specific anti-S. mansoni antibodies in animals which had never been exposed to the parasite antigen. The antibodies produced exhibited the same specificity for the $38 \mathrm{~K}$ molecule as the original $\mathrm{AB}_{1}$ monoclonal antibody used to produce the anti-idiotype antibody, suggesting that the $A_{2}$ produced may represent an internal image of the original epitope. However, most importantly, such experiments raise the possibility of inducing a strong immunity against schistosomes, as shown by both active immunization and passive transfer experiments. 


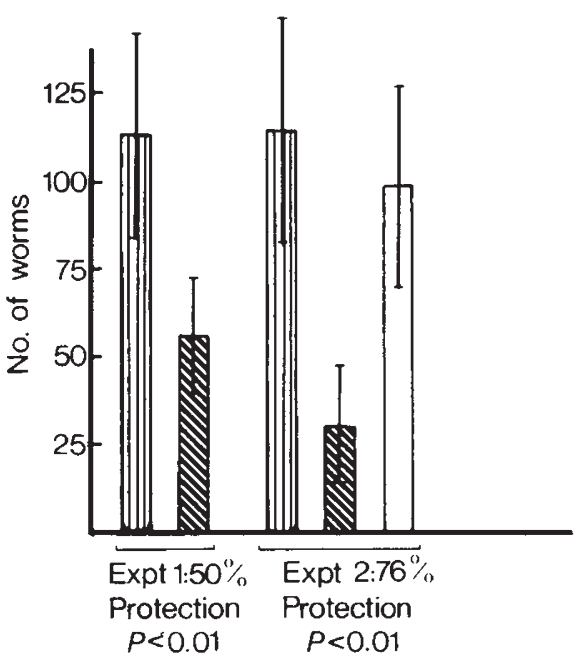

Fig. 4 Protective effect of JM8-36 immunization. LOU rats immunized as described in Fig. 2 legend, giving positive immunofluorescence reactions and significant eosinophil-dependent cytotoxicity, were infected with $800 \mathrm{~S}$. mansoni cercariae. Parasite burdens were measured 3 weeks later by liver perfusion ${ }^{16}$. The number of worms obtained from rats immunized with JM8-36 $\mathrm{AB}_{2}$ antibodies ( $)$ was compared with those obtained from control groups, that is LOU rats injected with physiological saline (Wll) or with IgM purified from normal rat serum $(\square)$. The percentage of protection was calculated by the formula $(a-b) / a \times 100$, where $a=$ the number of worms obtained from the saline-injected control group and $b=$ the number of worms recovered from $\mathrm{AB}_{2-}$ immunized rats.

Thus, immunization with anti-idiotype antibodies represents an alternative approach to immunization against pathogens. Although recent studies have produced encouraging results ${ }^{8-12}$ concerning the potential substitution of conventional vaccines by anti-idiotype antibodies, this strategy is only in its early stages $^{13}$. In the context of schistosomiasis, idiotype vaccines could be of particular use when relevant protective epitopes cannot easily be produced by the modern tools of molecular biology. Although the rat is a non-permissive host, there is now clear evidence ${ }^{14}$ that all the specific effector mechanisms of immunity described in this model also occur in human infection. The possibility of using such immunization procedures in humans remains unexplored and cannot be directly extrapolated from experimental infections. However, work in progress in our laboratory, indicating the existence of cross-reacting idiotypes in human schistosome infection, is encouraging.

We thank Claudine Colson for her help in the preparation of the manuscript. This work was supported by INSERM U167CNRS 624 and the WHO-UNDP Special Program for Research and Training in Tropical Diseases.

Received 18 February; accepted 24 April 1985.

1. Grzych, J. M., Capron, M., Bazin, H. \& Capron, A. J. Immun. 129, 2739-2743 (1982)

2. Dissous, C., Grzych, J. M. \& Capron, A. J. Immun. 129, 2232-2234 (1982)

3. Dissous, C., Prata, A. \& Capron, A. J. infect. Dis. 149, 227-233 (1984).

4. Grzych, J. M., Capron, M., Dissous, C. \& Capron, A. J. Immun. 133, 998-1004 (1984)

5. Jerne, N. K. Ann. Immun., Inst. Pasteur, Paris 125C, 373-389 (1974).

6. Bazin, H., Grzych, J. M., Verwaerde, C. \& Capron, A. Ann. Immun. Inst. Pasteur, Paris 131D, 359 (1980)

7. Capron, M. et al. Eur. J. Immun. 8, 127-133 (1978)

8. Sacks, D. L., Esser, K. M. \& Sher, A. J. exp. Med. 155, 1108-1119 (1982).

9. McNamara, M. K., Ward, R. E. \& Kohler, H. Science 226, 1325-1326 (1984)

10. Stein, K. E. \& Söderström, T. J. exp. Med. 160, 1001-1011 (1984)

11. Kennedy, R. C., Melnick, J. L. \& Dreesman, G. R. Science 223, 930-931 (1984)

12. Reagan, K. J., Wunner, W. H., Wiktor, T. J. \& Koprowski, H. J. Virol. 48, 660-666 (1983).

13. Sacks, D. L. in New Approaches to Vaccine Development (eds Bell, R. \& Torrigiani, G.) 121-131 (Schwabe, Basel, 1984).

14. Capron, A., Dessaint, J. P., Capron, M. \& Joseph, M. in Progress in Immunology Vol. 5 (eds Yamamura, Y. \&. Tada, T.) 1305-1316 (Academic, Tokyo, 1984).

15. Bazin, H., Beckers, A. \& Ouerinjean, P. Eur. J. Immun. 4, 44-48 (1974)

16. Smithers, S. R. \& Terry, R. J. Parasitology 55, 695-700 (1965).

\section{Individual-specific 'fingerprints' of human DNA}

\author{
A. J. Jeffreys*, V. Wilson* \& S. L. Thein $\dagger$ \\ * Department of Genetics, University of Leicester, University Road, \\ Leicester LE1 7RH, UK \\ † MRC Molecular Haematology Unit, Nuffield Department of \\ Clinical Medicine, John Radcliffe Hospital, Headington, \\ Oxford OX3 9DU, UK
}

Simple tandem-repetitive regions of DNA (or 'minisatellites') which are dispersed in the human genome frequently show substantial length polymorphism arising from unequal exchanges which alter the number of short tandem repeats in a minisatellite ${ }^{1-4}$. We have shown previously that the repeat elements in a subset of human minisatellites share a common 10-15-base-pair (bp) 'core' sequence which might act as a recombination signal in the generation of these hypervariable regions ${ }^{5}$. A hybridization probe consisting of the core repeated in tandem can detect many highly polymorphic minisatellites simultaneously to provide a set of genetic markers of general use in human linkage analysis ${ }^{5}$. We now show that other variant (core) $n$ probes can detect additional sets of hypervariable minisatellites to produce somatically stable DNA 'fingerprints' which are completely specific to an individual (or to his or her identical twin) and can be applied directly to problems of human identification, including parenthood testing.

Three human minisatellites, termed $33.5,33.6$ and 33.15, each comprised of tandem repeats of various versions of the core sequence, have been cloned previously and characterized ${ }^{5}$ (Fig.

Table 1 Similarities of DNA fingerprints between random pairs of individuals

\begin{tabular}{lcccc}
\hline Probe & $\begin{array}{c}\text { No. of } \\
\text { fragments } \\
\text { per } \\
\text { DNA }\end{array}$ & $\begin{array}{c}\text { Probability } \\
\text { f that } \\
\text { fragment } \\
\text { in A is } \\
\text { individual } \\
\pm \text { s.d. }\end{array}$ & $\begin{array}{c}\text { Maximum } \\
\text { mean } \\
\text { allelic } \\
\text { present in B }\end{array}$ & $\begin{array}{c}\text { frequency/ } \\
\text { homozygosity }\end{array}$ \\
& $10-20$ & $2.8 \pm 1.0$ & 0.11 & 0.06 \\
33.15 & $6-10$ & $5.1 \pm 1.3$ & 0.18 & 0.09 \\
& $4-6$ & $5.9 \pm 1.6$ & 0.28 & 0.14 \\
& $10-20$ & $2.9 \pm 1.0$ & 0.08 & 0.04 \\
& $6-10$ & $5.1 \pm 1.1$ & 0.20 & 0.10 \\
& $4-6$ & $6.7 \pm 1.2$ & 0.27 & 0.14 \\
\hline
\end{tabular}

Samples $(8 \mu \mathrm{g})$ of blood $\mathrm{DNA}^{6}$ taken from a random sample of 20 unrelated British caucasians were digested with Hinf I and Southern blot hybridized with minisatellite probes 33.6 or 33.15 as described in Fig. 1 legend. Each DNA fingerprint (individual A) was compared with the pattern in the adjacent gel track (individual B), and the number of bands in A which were clearly absent from B, plus those which had a co-migrating counterpart of roughly similar autoradiographic intensity in B, were scored. The data shown are averages for all pairwise comparisons. A small proportion $(\sim 6 \%)$ of additional weakly hybridizing fragments in A were matched by strongly hybridizing fragments in B, and because in such cases it was not possible to decide whether the band in $\mathrm{A}$ was also present in B, such fragments were ignored. If co-migrating bands in $A$ and $B$ are always identical alleles of the same minisatellite locus, then the probability $x$ that an allele in $\mathrm{A}$ is also present in B is related to the frequency $q$ of that allele by $x=2 q-q^{2}$. As the allele frequency is low, then $q^{2} \ll q$ and therefore the mean probability $\hat{x}$ is approximately related to the mean allele frequency $\hat{q}$ by $\hat{x} \simeq 2 \hat{q}$. Furthermore, assuming that there is little variance in $q$ between alleles, then the number of alleles $n \approx 1 / \hat{q}$ and the mean homozygosity is therefore approximately given by $\sum_{1}^{n} q_{i}^{2} \approx n \hat{q}^{2}=\hat{q}$. In practice, an (unknown) proportion of co-migrating bands in $A$ and $B$ will be derived by chance from different minisatellite loci, and thus the estimates of mean allele frequency and homozygosity are maximal and depend on the electrophoretic resolution of minisatellite fragments. Probability estimates: the mean probability that all fragments detected by probe 33.15 in individual $\mathrm{A}$ are also present in $\mathrm{B}$ is $0.08^{2.9} \times 0.20^{5.1} \times 0.27^{6.7}=$ $3 \times 10^{-11}$ 